\title{
Accelerated coronary calcium burden in breast cancer patients after radiotherapy: a comparison with age and race matched healthy women
}

Yu-Hsuan Lai ${ }^{1,2,4}$, Helen H. W. Chen ${ }^{1,2}$ and Yi-Shan Tsai ${ }^{3^{*}}$

\begin{abstract}
Background: Radiotherapy (RT) might lead to atherosclerotic plaque buildup and coronary artery stenosis of breast cancer (BC) survivors, and coronary artery calcium (CAC) might be a sign of preclinical atherosclerosis. This study explores possible determinants affecting the acceleration of CAC burden in BC patients after adjuvant RT.

Methods: Female BC patients receiving adjuvant RT from 2002 to 2010 were included. All patients received noncontrast computed tomography (NCCT) of thorax before and after adjuvant RT. Their CAC burden was compared with healthy controls from the Multi-Ethnic Study of Atherosclerosis (MESA) cohort. The progression of the CAC burden was manifested by the increment of CAC percentiles (\%CACinc).
\end{abstract}

Results: Ninety-four patients, including both left- and right-side BC, were enrolled in this study. From undergoing the first to second NCCT, the \%CACinc in BC patients significantly increased rather than non-BC women. In addition, the $\% C A C i n c$ was significantly higher in left-side than right-side BC patients $(p<0.05)$, and significant differences in most heart outcomes were found between the two groups. Besides, the lower the mean right coronary artery (RCA) dose, the lower the risks of CAC percentiles increase $\geq 50 \%$ after adjusting the disease's laterality.

Conclusions: $A$ significantly higher accelerated $C A C$ burden in $B C$ patients than non-BC women represents that $B C$ could affect accelerated CAC. A higher risk of accelerated CAC burden was found in left-side than right-side BC patients after adjuvant RT. A decrease of the mean RCA dose could reduce more than $50 \%$ of the risk of accelerated CAC burden in $B C$ patients.

Keywords: Coronary artery calcium, Breast cancer, CAC percentiles, Adjuvant radiotherapy

\section{Background}

Multimodality treatment strategies, including radiotherapy (RT), contribute to improve overall survival in breast cancer (BC) patients. This means a growing population of $\mathrm{BC}$ survivors would face late treatment-related toxicities,

\footnotetext{
*Correspondence: n506356@gmail.com

${ }^{3}$ Department of Medical Imaging, National Cheng Kung University Hospital, College of Medicine, National Cheng Kung University, No. 138 Sheng-Li Rd, Tainan, Taiwan

Full list of author information is available at the end of the article
}

including radiation-induced cardiac toxicity. Tangential field irradiation to the breast or chest wall holds the advantage in reducing radiation exposure to the contralateral breast/chest wall but remains some unwanted irradiation to the heart, especially in left-side BC. Studies have shown that the cumulative incidence of acute coronary events increases by $16.5 \%$ per Gray (Gy) of mean heart dose (MHD) [1, 2]. RT cardiotoxicity might occur decades after radiation and earlier in patients with original author(s) and the source, provide a link to the Creative Commons licence, and indicate if changes were made. The images or other third party material in this article are included in the article's Creative Commons licence, unless indicated otherwise in a credit line to the material. If material is not included in the article's Creative Commons licence and your intended use is not permitted by statutory regulation or exceeds the permitted use, you will need to obtain permission directly from the copyright holder. To view a copy of this licence, visit http://creativecommons.org/licenses/by/4.0/. The Creative Commons Public Domain Dedication waiver (http://creativeco mmons.org/publicdomain/zero/1.0/) applies to the data made available in this article, unless otherwise stated in a credit line to the data. 
pre-existing risk factors or disease, regardless of chemotherapy [3].

The heart had been thought of a radioresistant organ. However, there is increasing evidence supporting that the heart is actually a dose-limiting organ in RT $[4,5]$. The pathogenesis of radiation-induced coronary artery disease is complex and cardiac dysfunction and subsequent heart failure might be due to vascular toxicity and myocardial ischemia [6]. Radiation-induced heart disease includes a series of harmful effects on the heart, from subclinical histopathological findings to obvious clinical diseases. The effect of damaging the heart may be manifested in the pericardium, myocardium, valves, conduction system, or coronary arteries. Earlier studies explore that the coronary arteries are particularly radiosensitive, and the vascular damage might be responsible for longterm radiation-induced ischemic heart disease [7-9]. The effects of local RT to the blood vessels cause proinflammatory responses such as increased wall permeability, release of reactive oxygen, inflammatory agents and increased frequency of intraplaque hemorrhage [10], leading to atherosclerotic plaque buildup and coronary artery stenosis. These deposited plaques are often calcified so that coronary artery calcium (CAC) can be served as a sign of preclinical atherosclerosis. The quantification of CAC, absolute CAC scores, has been reported as an important prognostic imaging biomarker for future coronary artery disease (CAD) in asymptomatic individuals [11-13]. There is currently strong evidence that the higher the CAC scores, the higher the risks of acute coronary events [14-17]. An extra benefit of CAC scoring is that the presence and number of calcified plaques in the coronary arteries are determined by a non-invasive tool, a noncontrast computed tomography (NCCT) scan of thorax, thus facilitates its clinical use.

Until today, the clinically valuable dose constraint for the coronary arteries is not yet fully established. Most studies take the MHD as a surrogate parameter in evaluating radiation-associated cardiac toxicity, but whether this parameter can reflect the real condition of coronary arteries remains uncertain. Therefore, higher radiation doses were hypothesized to correlate with the acceleration of calcium deposits in coronary arteries. The dosimetric data of three main coronary arteries from CTbased planning system were analyzed and drew a new concept, the increment of CAC percentiles (\%CACinc), to manifest the acceleration of coronary calcium burden before and after adjuvant RT. This study aimed to explore the relationship of accelerated coronary calcium burden and coronary radiation doses in $\mathrm{BC}$ patients receiving adjuvant RT. Furthermore, whether the progression of coronary calcium deposits is affected by other cardiotoxic therapeutic agents such as anthracycline, taxane, or trastuzumab, remains debatable. The impact of a variety of treatment and cardiovascular risk factors on the increment of coronary calcium burden was also investigated.

\section{Materials and methods Patients}

From January 2002 to September 2010, 94 consecutive female patients aged 45 to 84 years with pathologically diagnosed $\mathrm{BC}$ who underwent mastectomy or breastconserving surgery (BCS) and a complete course of adjuvant $\mathrm{RT}$ with a total dose of $\geqq 50$ Gy at our institution were included. Each patient received two series of NCCT scans of thorax, one before RT and the other at least one year after RT. The patients who received adjuvant RT for locoregional recurrent disease or inoperable tumor or those who received internal mammary nodal irradiation were excluded. The patients with a history of cigarette smoking, CAD, arrhythmia, and stroke before receiving RT were also excluded. The patient data, including age, laterality of tumor, pathological stage, treatment-related profiles (type of surgery, chemotherapy, hormone therapy, targeted therapy), cardiovascular risk factors such as diabetes, hypertension, hyperlipidemia, and body mass index (BMI), were gathered from the hospital medical records. In Taiwan, the Ministry of Health and Welfare defined overweight at $\mathrm{BMI} \geqq 24 \mathrm{~kg} / \mathrm{m}^{2}$ and obese at BMI $\geqq 27 \mathrm{~kg} / \mathrm{m}^{2}$. The Tumor, Node, Metastasis (TNM) stage determined previously was revised based on the Seventh Edition of the American Joint Committee on Cancer (AJCC) Stating System [18]. Institutional Review Board approved this retrospective study.

\section{Non-BC women as a control group}

Non-BC women with cardiovascular risk factors such as diabetes, hypertension, and hyperlipidemia without a history of cigarette smoking, CAD, arrhythmia, or stroke before NCCT were included in this study. Finally, 47 non$\mathrm{BC}$ women aged from 45 to 84 years who underwent two series of NCCT scans of thorax with a time interval of at least one year at our institution were collected as a control group. The values of CAC percentiles and \%CACinc were calculated as methods mentioned below.

\section{Radiation therapy dose and techniques}

Our treatment plan was designed based on these studies [19-21]. Tangential techniques were used for the chest wall/breast irradiation. Two $180^{\circ}$ opposed isocentric tangential fields with half-beam block techniques were set up according to the clinically determined borders. For mastectomy patients, a median dose of 50 Gy in 1.8-2 Gy per fraction was given to the chest wall, with an additional scar boost dose of 10-20 Gy in T4 disease or close/ positive surgical margins. For BCS patients, a median 
dose of 50 Gy in 1.8-2 Gy per fraction was given to the whole breast, followed by a median boost dose of another 10-16 Gy to the tumor bed. Boost field was delivered with appositional field using electrons or intensity-modulated radiotherapy (IMRT) fields using photons. Regional nodal radiation was tailored to the individual patient at the discretion of the treating physicians.

\section{Contouring of coronary arteries and dosimetry}

Since the CT-based planning system was introduced from August 2006 onwards in our institution, dosimetric data were available in 75 patients. The CT-based planning was based on a NCCT scan of thorax before adjuvant $\mathrm{RT}$, with CT-slice thickness of $0.5 \mathrm{~cm}$. The organs at risk (OARs), including the heart, left anterior descending artery (LAD), left circumflex artery (LCX), and right coronary artery (RCA), were contoured for dosimetric calculation according to the guidance of the validated University of Michigan cardiac atlas [22]. Sometimes it was hard to visualize the coronary arteries directly on the NCCT images. Therefore, the delineation of coronary arteries was conducted based on their anatomic courses and inferred by visible landmarks of the heart. Both the LAD and LCX branched from the left main coronary artery (LMCA), and were outlined by the anterior interventricular groove and left atrioventricular groove. The RCA emerged from the aorta and was identified by the right atrioventricular groove and posterior interventricular sulcus. The contouring of OARs was conducted by a 14-year-experienced cardiovascular radiologist. The dose-volume histograms (DVHs) were generated for the planning target volume (PTV) and OARs. Dosimetric comparisons were made between patients with left-side and right-side $\mathrm{BCs}$.

\section{Determination of absolute coronary artery calcium score (CACinc)}

The absolute CAC score was estimated using a non-electrocardiography (ECG)-gated CT scan of thorax [23, 24] and calculated by commercially available calcium scoring software (Aquarius iNtuition software Version 4.4.7, TeraRecon, Inc, San. Mateo, CA, USA). Each patient's two series of CT scans before and after adjuvant RT were evaluated by the same cardiovascular radiologist to determine the increment of absolute CAC (CACinc) of coronary artery, including LMCA, LAD, LCX, and RCA. The calcified lesions were selected and labeled, and those above a standard threshold of 130 Hounsfield units (HU) were considered candidate calcifications. The scalar given to the peak $\mathrm{HU}$ number in the lesion in question was as follows: $1: \leq 200 \mathrm{HU}, 2: 200-299 \mathrm{HU}, 3: 300-399 \mathrm{HU}$, and 4: $400+$ HU. The modified Agatston score [14] was calculated by multiplying the area of the calcified lesion by a scalar, and the sum of all these slice-by-slice calculations was taken to generate the total score for a three-dimensional (3D) lesion.

\section{Age, gender, race/ethnicity specific CAC percentiles by comparison with the MESA cohort}

The Multi-Ethnic Study of Atherosclerosis (MESA) study was designed to examine whether a patient had a high CAC score relative to a healthy and asymptomatic participant with the same age, gender, and race/ethnicity [25]. Patients with ages less than 45 years and more than 84 years were excluded from this study because these two age groups were not included in the MESA cohort. The CAC scores of the $94 \mathrm{BC}$ patients aged 45-84 years were compared with those of their age-matched female Asian MESA cohort and then translated into CAC percentiles; for example, the 75th percentile meant that the given value of CAC score was higher than those of $75 \%$ healthy populations. The progression of coronary calcium burden was manifested by the \%CACinc, defined as the difference of two CAC percentiles before and after adjuvant RT.

$$
\begin{aligned}
\% \text { CACinc }= & \text { CAC percentile after RT } \\
& - \text { CAC percentile before RT }
\end{aligned}
$$

\section{Statistical analysis}

Baseline characteristics were presented as median (first and third quartile) for continuous variables and number (frequency) for categorical variables. P-value of continuous variables was calculated by Mann-Whitney $U$ test or Kruskal-Wallis test whereas p-value of categorical variables was calculated by Chi-square test and Fisher's exact test. Comparison of the two CAC percentiles of total BC patients, left-side and right-side $\mathrm{BC}$ patients, and non$\mathrm{BC}$ women was performed by paired t-test. Comparison of \%CACinc between left-side and right-side $\mathrm{BC}$ patients was performed by Mann-Whitney U test. Regression of $\%$ CACinc and clinical factors were executed by linear regression. Spearman correlation was used to calculate the association of \%CACinc and dosimetric variables. Logistic regression was used to calculated odds ratio of dosimetric variables which led to \%CACinc increase more than $50 \%$. All statistical results were calculated with SAS 9.4 software (SAS Institute, Carry, NC). A two-tailed $P$ value $<0.05$ was considered significant.

\section{Results}

A total of 94 patients were enrolled in this study, including 51 left-side (54.3\%) and 43 right-side (45.7\%) BC patients. No significant difference of clinical characteristics was presented between left-side and right-side 
Table 1 Baseline characteristic of breast cancer patient population

\begin{tabular}{|c|c|c|c|c|}
\hline \multirow[t]{2}{*}{ Characteristic } & \multirow[t]{2}{*}{ Total } & \multicolumn{2}{|l|}{ Breast cancer } & \multirow[t]{2}{*}{$\mathrm{p}$ value } \\
\hline & & Left-side BC & Right-side BC & \\
\hline Number of patients & 94 & $51(54.3 \%)$ & $43(45.7 \%)$ & \\
\hline Age at 1st NCCT (years) & $53(45-78)$ & $52(45-74)$ & $55(45-78)$ & 0.461 \\
\hline Age at 2nd NCCT (years) & $60(48-80)$ & $60(48-80)$ & $62(48-79)$ & 0.371 \\
\hline NCCT interval (years) & $6.9(1.0-12.6)$ & $6.8(1.1-12.6)$ & $7.3(1.0-11.7)$ & 0.664 \\
\hline Pathological stage & & & & 0.292 \\
\hline 0 & $2(2.1 \%)$ & $0(0.0 \%)$ & $2(4.7 \%)$ & \\
\hline । & $13(13.8 \%)$ & $9(17.6 \%)$ & $4(9.3 \%)$ & \\
\hline$\|$ & $28(29.8 \%)$ & $15(29.4 \%)$ & $13(30.2 \%)$ & \\
\hline III & $47(50.0 \%)$ & $26(51.0 \%)$ & $21(48.8 \%)$ & \\
\hline IV & $4(4.3 \%)$ & $1(2.0 \%)$ & $3(7.0 \%)$ & \\
\hline Surgery & & & & 0.952 \\
\hline BCS & $32(34.0 \%)$ & $18(35.3 \%)$ & $14(32.6 \%)$ & \\
\hline Mastectomy & $62(66.0 \%)$ & $33(64.7 \%)$ & $29(67.4 \%)$ & \\
\hline Chemotherapy & & & & 0.882 \\
\hline Yes & $77(81.9 \%)$ & $41(80.4 \%)$ & $36(83.7 \%)$ & \\
\hline No & $17(18.1 \%)$ & $10(19.6 \%)$ & $7(16.3 \%)$ & \\
\hline Anthracycline or Taxane regimen & 0.699 & & & \\
\hline Yes & $76(80.9 \%)$ & $40(78.4 \%)$ & $36(83.7 \%)$ & \\
\hline No & $18(19.1 \%)$ & $11(21.6 \%)$ & $7(16.3 \%)$ & \\
\hline Hormone therapy & & & & 0.623 \\
\hline Yes & $71(75.5 \%)$ & $37(72.5 \%)$ & $34(79.1 \%)$ & \\
\hline No & $23(24.5 \%)$ & $14(27.5 \%)$ & $9(20.9 \%)$ & \\
\hline Targeted therapy (Trastuzumab) & & & & 0.468 \\
\hline Yes & $5(5.3 \%)$ & $4(7.8 \%)$ & $1(2.3 \%)$ & \\
\hline No & $89(94.7 \%)$ & 47 (92.2\%) & $42(97.7 \%)$ & \\
\hline BMI (overweight) & & & & 0.705 \\
\hline$\geqq 24$ & $49(52.1 \%)$ & $28(54.9 \%)$ & $21(48.8 \%)$ & \\
\hline$<24$ & $45(47.9 \%)$ & $23(45.1 \%)$ & $22(51.2 \%)$ & \\
\hline BMI (obese) & & & & 0.169 \\
\hline$\geqq 27$ & $25(26.6 \%)$ & $17(33.3 \%)$ & $8(18.6 \%)$ & \\
\hline$<27$ & $69(73.4 \%)$ & $34(66.7 \%)$ & $35(81.4 \%)$ & \\
\hline Diabetes & & & & 0.838 \\
\hline Yes & $15(16.0 \%)$ & $8(15.7 \%)$ & $7(16.3 \%)$ & \\
\hline No & $79(84.0 \%)$ & $43(84.3 \%)$ & $36(83.7 \%)$ & \\
\hline Hypertension & & & & 0.180 \\
\hline Yes & $20(21.3 \%)$ & 14 (27.5\%) & $6(14.0 \%)$ & \\
\hline No & 74 (78.7\%) & 37 (72.5\%) & 37 (86.0\%) & \\
\hline Hyperlipidemia & & & & 0.142 \\
\hline Yes & $13(13.8 \%)$ & 10 (19.6\%) & $3(7.0 \%)$ & \\
\hline No & $81(86.2 \%)$ & 41 (80.4\%) & 40 (93.0\%) & \\
\hline
\end{tabular}

$B C$ breast cancer, NCCT noncontrast computed tomography, $B C S$ breast-conserving surgery, $B M I$ body mass index

BC patients (Table 1). Before adjuvant RT, 92 out of 94 patients had zero CAC percentiles, and 68 patients still being zero after receiving adjuvant RT. Twentysix patients had positive \%CACinc after adjuvant RT, 19 left-side and 7 right-side $\mathrm{BC}$ patients. The mean values of \%CACinc from the first to second NCCT were $18.4 \%, 25.3 \%, 10.2 \%$, and $2.7 \%$ in total, left-side, rightside $\mathrm{BC}$ patients, and non-BC women, respectively (Table 2). \%CACinc was significantly higher in left-side than right-side $\mathrm{BC}$ patients (Fig. 1). The possible factors 
Table 2 Comparison of CAC percentiles between the first and second NCCT in all participants of this study

\begin{tabular}{lllll}
\hline CAC percentiles & Total BC $(\mathbf{n}=\mathbf{9 4})$ & Left-side BC $(\mathbf{n}=\mathbf{5 1})$ & Right-side BC $(\mathbf{n}=\mathbf{4 3})$ & Non-BC $(\mathbf{n}=\mathbf{4 7})$ \\
\hline No increment (zero vs. zero) & 68 & 32 & 36 & 30 \\
Positive increment & 26 & 19 & 7 & 13 \\
$\quad$ Zero vs. non-zero & 24 & 18 & 6 & 1 \\
Non-zero vs. non-zero & 2 & 1 & 1 & 12 \\
Positive increment $\geq 50 \%$ & 22 & 17 & 5 & 1 \\
Mean \%CACinc value & $18.4 \%$ & $25.3 \%$ & $10.2 \%$ & $2.7 \%$ \\
p value & $<\mathbf{0 . 0 0 0 1}$ & $<\mathbf{0 . 0 0 0 1}$ & $\mathbf{0 . 0 0 9 6}$ & 0.1551
\end{tabular}

CAC coronary artery calcium, NCCT noncontrast computed tomography, $B C$ breast cancer, $n$ number of patients, \%CACinc increment of CAC percentiles Significant difference with $p$ value $<0.05$ were shown in bold

Increment of CAC percentile

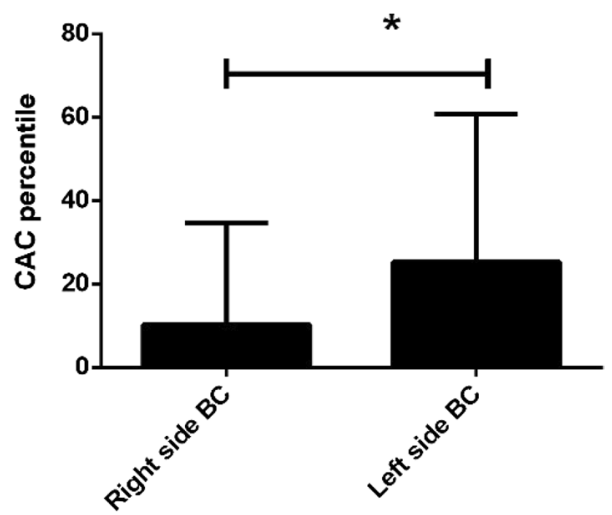

Fig. 1 Comparison of increment of CAC percentile (\%CACinc) in patients with left-side versus right-side breast cancer

contributing to clinical characteristics on \%CACinc were evaluated in Table 3. \%CACinc was increased by $15.13 \%$ in left-side $\mathrm{BC}$ patients compared with right-side $\mathrm{BC}$ patients $(\mathrm{p}=0.02)$, probably because parts of the heart were close to or in the left tangential irradiation fields (Fig. 2). The dosimetric variables between two sides BC patients were analyzed, and results showed that MHD, maximum heart dose, heart V25, mean LAD dose, maximum LAD dose, mean LCX dose, maximum LCX dose, and mean RCA dose were significantly different between two groups (Table 4). The correlations between dosimetric variables were calculated in Table 5 , suggesting that MHD, maximum heart dose, mean LAD dose were negatively correlated among dosimetric parameters in rightside BC patients. Besides, mean RCA dose was negatively correlated among dosimetric parameters in right-side $\mathrm{BC}$ patients and the overall $\mathrm{BC}$ population. We further divided all $\mathrm{BC}$ patients into two groups: \%CACinc $\geq 50 \%$ group and \%CACinc $<50 \%$ group, and calculated the risks of dosimetric variables which led to increasing more than 50\% CAC percentile. After adjusting the laterality of disease, the maximum heart dose did not increase the risks of \%CACinc (aOR of 1.015), but the mean RCA dose significantly decreased the risks of enhancing the $\%$ CACinc with an aOR of $0.47(\mathrm{p}=0.039)$ (Table 6).

\section{Discussion}

In this study, a new concept of the \%CACinc was drawn to display the progression of coronary calcium burden in BC patients. After second NCCT, the accelerated $\mathrm{CAC}$ burden in $\mathrm{BC}$ patients was significantly higher than that in non-BC women. None of the different cardiotoxic therapeutic agents, treatment, and cardiovascular risk factors was observed to influence the increment of \%CACinc in BC patients. After adjuvant RT, the left-side $\mathrm{BC}$ patients had a higher risk of accelerated coronary calcium burden after adjusting age, race, and gender compared to the healthy MESA cohort. Besides, reducing RCA dose significantly decreased the risks of CAC percentiles increase $\geq 50 \%$ after adjusting the disease's laterality.

Our study was the first to introduce the concept of the \%CACinc to manifest the progression of coronary calcium burden. The reasons why the age-, race-, and gender-matched CAC percentiles were selected instead of absolute $\mathrm{CAC}$ scores as a predictive tool were shown as followed: Firstly, age was a significant risk factor for the acceleration of coronary atherosclerosis. The more aged is, the higher probability of non-zero coronary calcium score is. For example, the estimated probability of a non-zero coronary calcium score for a Chinese woman was $16 \%$ in 50 while $55 \%$ in 70 [25]. If the age confounder is not corrected, there might be a problem of over or under-estimate of the effect from other risk factors on the progression of coronary calcium burden. Secondly, race/ethnicity was also a confounder for the predictive value of coronary calcium burden due to different lifestyles among races causing different exposures to cardiovascular risk factors, such as more dietary consumption, less physical activity, higher BMI, or 
Table 3 Possible determinants affecting increment of CAC percentiles in breast cancer patients

\begin{tabular}{|c|c|c|}
\hline Variables & $\beta(95 \% \mathrm{Cl})$ & $\mathrm{p}$ value \\
\hline \multicolumn{3}{|l|}{ Laterality of disease } \\
\hline Right-side BC & Ref & Ref \\
\hline Left-side BC & $15.13(2.37,27.87)$ & 0.020 \\
\hline \multicolumn{3}{|l|}{ Pathology stage } \\
\hline । & Ref & Ref \\
\hline$\|$ & $-10.46(-30.09-9.17)$ & 0.296 \\
\hline III & $-5.71(-23.90-12.49)$ & 0.539 \\
\hline IV & $-17.07(-51.09-17.46)$ & 0.333 \\
\hline \multicolumn{3}{|l|}{ Pathology stage } \\
\hline O vs. I vs. II & Ref & Ref \\
\hline III vs. IV & $0.215(-12.90,13.33)$ & 0.974 \\
\hline \multicolumn{3}{|l|}{ Surgery } \\
\hline Mastectomy & Ref & Ref \\
\hline $\mathrm{BCS}$ & $-3.08(-16.85,10.70)$ & 0.659 \\
\hline \multicolumn{3}{|l|}{ Chemotherapy } \\
\hline No & Ref & Ref \\
\hline Yes & $-6.94(-23.86,9.98)$ & 0.417 \\
\hline \multicolumn{3}{|l|}{ Hormone therapy } \\
\hline No & Ref & Ref \\
\hline Yes & $-2.10(-17.29,13.10)$ & 0.785 \\
\hline \multicolumn{3}{|l|}{ Targeted therapy } \\
\hline No & Ref & Ref \\
\hline Yes & $-6.10(-35.19,22.10)$ & 0.678 \\
\hline \multicolumn{3}{|l|}{ Overweight } \\
\hline $\mathrm{BMI}<24$ & Ref & Ref \\
\hline $\mathrm{BMI} \geqq 24$ & $-6.19(-19.21,6.83)$ & 0.347 \\
\hline \multicolumn{3}{|l|}{ Obese } \\
\hline $\mathrm{BMl}<27$ & Ref & Ref \\
\hline $\mathrm{BMI} \geqq 27$ & $1.18(-13.61,15.97)$ & 0.874 \\
\hline \multicolumn{3}{|l|}{ Diabetes } \\
\hline No & Ref & Ref \\
\hline Yes & $13.99(-3.62,31.60)$ & 0.118 \\
\hline \multicolumn{3}{|l|}{ Hypertension } \\
\hline No & Ref & Ref \\
\hline Yes & $1.62(-14.34,17.59)$ & 0.841 \\
\hline \multicolumn{3}{|l|}{ Hyperlipidemia } \\
\hline No & Ref & Ref \\
\hline Yes & $-1.59(-20.52,17.34)$ & 0.867 \\
\hline Total irradiation dose (Gy) & $-0.37(-1.32,0.58)$ & 0.439 \\
\hline
\end{tabular}

$C A C$ coronary artery calcium, $B C$ breast cancer, $B C S$ breast-conserving surgery, $B M I$ body mass index, Gy gray

Significant $p$ value was in bold

more current or former smokers. Therefore, using age-, race-, gender-matched CAC percentiles by comparison with the MESA cohort instead of using absolute CAC scores would, theoretically, be better reflect the real impact of treatment or other cardiovascular risk factors

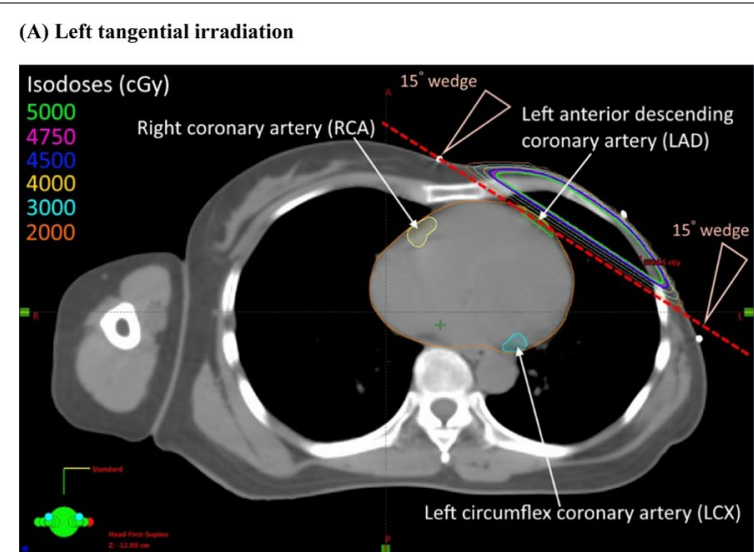

(B) Right tangential irradiation

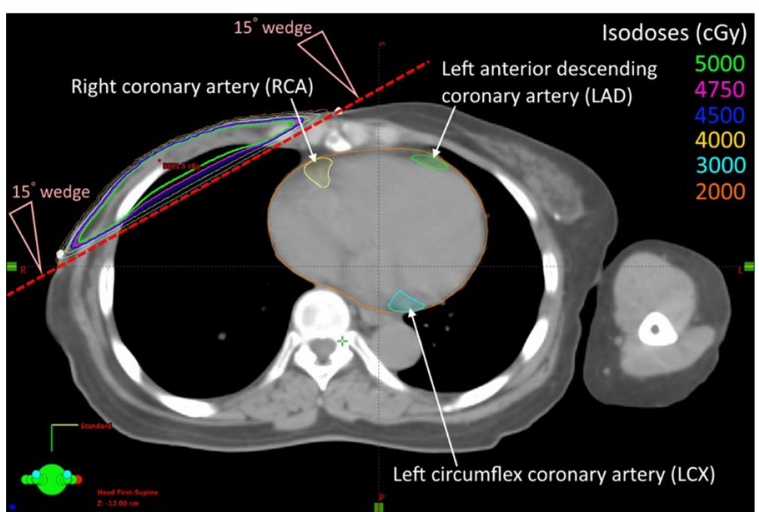

Fig. 2 Dose distribution from $6 \mathrm{MV}$ tangential irradiation with $15^{\circ}$ wedge in left-side (a) and right-side (b) breast cancers after mastectomy. The organs at risk (OARs) including the heart, left anterior descending coronary artery (LAD), left circumflex artery $(\mathrm{LCX})$, and right coronary artery $(\mathrm{RCA})$ were outlined

on the increment of coronary calcium burden in $\mathrm{BC}$ patients.

Our result indicated that left-side BC patients had a higher risk of accelerated coronary calcium burden after adjuvant RT. It remained debatable for the influence of the laterality of BC on the CAC level [26, 27]. Nevertheless, radiation exposure to cardiac structures is the only significant difference between left- and right-side BCs, and radiation appears to be an independent risk factor of arteriosclerosis [9]. The risk of cardiac toxicity due to adjuvant RT could begin within a few years after treatment and may continue for more than 15 years. Recent studies showed that a significant decrease in cardiac and left coronary artery doses is likely to reduce longterm side effects [28]. Previous epidemiological studies on post-radiotherapy cardiotoxicity showed that the MHD doses are typically described as those received by the entire heart, and it may thus be a dose criterion for RT-induced cardiotoxicity $[29,30]$. In a large populationbased case-control study published by Darby et al. [1], 
Table 4 Dosimetric parameters in left-side and right-side tangential irradiation

\begin{tabular}{|c|c|c|c|}
\hline \multirow{2}{*}{$\begin{array}{l}\text { Dosimetric } \\
\text { parameter }\end{array}$} & \multicolumn{2}{|c|}{ Population $(n=75)$} & \multirow[t]{2}{*}{$p$ value } \\
\hline & $\begin{array}{l}\text { Left-side BC } \\
(n=41) \text { Mean } \\
( \pm S D)\end{array}$ & $\begin{array}{l}\text { Right-side BC } \\
(\mathrm{n}=34) \text { Mean } \\
( \pm \text { SD) }\end{array}$ & \\
\hline $\begin{array}{l}\text { Total irradiation dose } \\
\text { (Gy) }\end{array}$ & $57.6( \pm 6.8)$ & $58.2( \pm 6.6)$ & 0.711 \\
\hline Mean heart dose (Gy) & $4.2( \pm 1.4)$ & $1.2( \pm 0.6)$ & $<0.001$ \\
\hline $\begin{array}{l}\text { Maximum heart dose } \\
\text { (Gy) }\end{array}$ & $51.6( \pm 7.9)$ & $5.1( \pm 1.9)$ & $<0.001$ \\
\hline Heart V25 (\%) & $4.0( \pm 2.6)$ & 0 & $<0.001$ \\
\hline Heart volume $\left(\mathrm{cm}^{3}\right)$ & $572.9( \pm 123.3)$ & $573.5( \pm 76.3)$ & 0.982 \\
\hline Mean LAD dose (Gy) & $19.6( \pm 9.7)$ & $1.2( \pm 0.7)$ & $<0.001$ \\
\hline $\begin{array}{l}\text { Maximum LAD dose } \\
\text { (Gy) }\end{array}$ & $50.7( \pm 7.2)$ & $2.1( \pm 1.2)$ & $<0.001$ \\
\hline LAD volume $\left(\mathrm{cm}^{3}\right)$ & $10.0( \pm 4.7)$ & $10.2( \pm 4.1)$ & 0.856 \\
\hline Mean LCX dose (Gy) & $1.5( \pm 0.7)$ & $0.4( \pm 0.2)$ & $<0.001$ \\
\hline $\begin{array}{l}\text { Maximum LCX dose } \\
\text { (Gy) }\end{array}$ & $2.5( \pm 2.1)$ & $0.7( \pm 0.3)$ & $<0.001$ \\
\hline Mean RCA dose (Gy) & $2.1( \pm 0.8)$ & $2.7( \pm 0.9)$ & $<0.01$ \\
\hline $\begin{array}{l}\text { Maximum RCA dose } \\
\text { (Gy) }\end{array}$ & $5.1( \pm 7.5)$ & $4.6( \pm 1.8)$ & 0.703 \\
\hline
\end{tabular}

an increased risk of major coronary events was linearly correlated with MHD by 7.4\% per Gy. Another study for Fannish and Swedish subjects announced an elevated risk of heart disease was correlated with MHD by $4 \%$ per Gy [31]. However, our data failed to demonstrate a significant association between MHD and \%CACinc. Jacob et al. [32] reported that MHD is not enough to predict with confidence individual patient dose to the left ventricle and LAD, and considering the distribution of doses within these cardiac substructures rather than just the MHD is necessary. Conclusively, there is still no clear consensus on the dose constraints for the heart and coronary arteries in $\mathrm{BC}$ patients receiving adjuvant $\mathrm{RT}$. In the era of CT-based planning system, whenever possible, the integration of the coronary artery anatomy into RT planning is encouraged, especially in left-side BC irradiation.

In this study, there is an ambiguous relation between accelerated CAC burden and coronary radiation doses. MHD, maximum heart dose, mean LAD dose, and mean RCA dose showed a significant difference between leftside and right-side adjuvant RT and negatively correlated with each other. However, the increase of MHD, maximum heart dose, and mean LAD dose cannot significantly reflect the higher risk of \%CACinc. Besides, the multivariate analysis showed that reducing RCA dose significantly decreased the risks of CAC percentiles increase more than $50 \%$ after adjusting the disease's laterality. It might be due to the anatomical position of the RCA. The opening and the mesial part of the RCA are closer to the thoracic cavity than the opening and the proximal portion of the LAD, which might lead to more dosage disturbance of adjuvant RT to RCA, either in left-side or right-side RT. The mean RCA dose might also be an alternative predictor for increment CAC burden in $\mathrm{BC}$ patients after adjuvant RT. Further studies are warranted to confirm this thought.

\section{Limitation}

There are several limitations in this study. Firstly, the NCCT scan of thorax was not routinely applied as an initial staging or a follow-up exam for BC patients, thus limited this study's populations. Some pre-treatment images to determine the baseline CAC values were obtained from simulation $\mathrm{CT}$ scans for adjuvant RT treatment planning. During simulation CT scan

Table 5 Correlation between dosimetric parameters in left-side and right-side tangential irradiation and increment of CAC percentiles

\begin{tabular}{|c|c|c|c|c|c|c|}
\hline & \multicolumn{2}{|c|}{ Overall BC $(n=75)$} & \multicolumn{2}{|c|}{ Left-side $B C(n=41)$} & \multicolumn{2}{|c|}{ Right-side BC $(n=34)$} \\
\hline & Correlation & $p$ value & Correlation & p value & Correlation & $p$ value \\
\hline Mean heart dose (Gy) & 0.021 & 0.855 & -0.187 & 0.241 & -0.44 & 0.009 \\
\hline Maximum heart dose (Gy) & 0.191 & 0.101 & 0.09 & 0.576 & -0.375 & 0.029 \\
\hline Heart V25 (\%) & 0.068 & 0.565 & -0.124 & 0.439 & 0 & NA \\
\hline Mean LAD dose (Gy) & 0.144 & 0.215 & 0.004 & 0.977 & -0.34 & 0.049 \\
\hline Maximum LAD dose (Gy) & 0.199 & 0.088 & 0.106 & 0.510 & -0.301 & 0.080 \\
\hline Mean LCX dose (Gy) & 0.106 & 0.366 & -0.021 & 0.894 & -0.274 & 0.116 \\
\hline Maximum LCX dose (Gy) & 0.057 & 0.626 & -0.123 & 0.442 & -0.275 & 0.116 \\
\hline Mean RCA dose (Gy) & -0.284 & 0.013 & -0.129 & 0.423 & -0.425 & 0.010 \\
\hline
\end{tabular}

$C A C$ coronary artery calcium, $B C$ breast cancer, $n$ number of patients, Gy gray, $L A D$ left anterior descending artery, $L C X$ left circumflex artery, $R C A$ right coronary artery $\mathrm{P}$-value was calculated by spearman correlation. Significant $\mathrm{p}$ value was in bold 
Table 6 Risks of CAC percentiles increase $\geq 50 \%$ between dosimetric parameters

\begin{tabular}{lllcc}
\hline & Univariate & & Multivariate \\
\cline { 2 - 3 } & Odds ratio & p value & Odds ratio & p value \\
\hline Mean heart dose (Gy) & $1.042(0.775-1.401)$ & 0.787 & $0.584(0.332-1.026)$ & 0.061 \\
Maximum heart dose (Gy) & $1.024(0.998-1.05)$ & 0.070 & $1.015(0.92-1.121)$ & 0.760 \\
Mean LAD dose (Gy) & $1.033(0.987-1.081)$ & 0.165 & $1(0.999-1.001)$ & 0.998 \\
Mean RCA dose (Gy) & $\mathbf{0 . 4 2 9 ( 0 . 2 1 5 - 0 . 8 5 9 )}$ & $\mathbf{0 . 0 1 7}$ & $\mathbf{0 . 4 7}(\mathbf{0 . 2 2 9 - 0 . 9 6 2 )}$ & $\mathbf{0 . 0 3 9}$ \\
\hline
\end{tabular}

$C A C$ coronary artery calcium, Gy gray, $L A D$ left anterior descending artery, $R C A$ right coronary artery

Significant $p$ value was in bold

acquisition, patients were instructed to breathe freely, and no ECG triggering was utilized. These compromised the image quality by allowing cardiac motion, high noise levels, and partial volume effect [33, 34]. However, several studies demonstrated the feasibility of CAC quantification from non-triggered CT scans [24, 34-37] and showed good concordance between gated and non-gated CAC scoring [24, 35]. Using the non-triggered planning $\mathrm{CT}$ scans to evaluate pre-treatment CAC values can help reduce radiation exposure and medical costs compared to additional CT scans, and be quickly drawn for clinical routine. Secondly, the patients in the study were treated with a conventional technique (tangentially opposed fields) with sequential boost, which might be a limitation in reducing cardiac dose. Several advanced techniques, such as hypofractionated RT with concomitant boost [20], IMRT with simultaneous integrated boost (SIB) [21], or deep inspiration breath-hold (DIBH) [38], help lower cardiac radiation dose. Thirdly, the dosimetric data of 19 of 94 BC patients in this study was missing, which might bias the statistical analysis. Finally, the length of the time interval between two CT scans in a small group of patients was as short as one year, which was likely not long enough to make a valuable assessment of an incremental change in coronary calcium deposition.

\section{Conclusion}

In conclusion, this study revealed that the accelerated $\mathrm{CAC}$ burden in $\mathrm{BC}$ patients is significantly higher than that in non-BC women, representing that $B C$ might influence the progression of CAC burden. Furthermore, a significantly higher risk of accelerated $C A C$ burden was found in left-side than right-side $\mathrm{BC}$ patients after adjuvant RT. Besides, a decrease of the mean RCA dose could reduce more than $50 \%$ of the risk of accelerated CAC burden in BC patients. Further large-scale studies are warranted to confirm this finding.

\section{Abbreviations}

CAC: Coronary artery calcium; BC: Breast cancer; RT: Radiotherapy; NCCT: Noncontrast computed tomography; MESA: Multi-Ethnic Study of Atherosclerosis; \%CACinc: Increment of CAC percentiles; MHD: Mean heart dose; LAD: Left anterior descending artery; LCX: Left circumflex artery; RCA: Right coronary artery; Gy: Gray; CAD: Coronary artery disease; BCS: Breast-conserving surgery; BMI: Body mass index; TNM: Tumor, node, metastasis; AJCC: American Joint Committee on Cancer; IMRT: Intensity-modulated radiotherapy; OARs: Organs at risk; LMCA: Left main coronary artery; DVHs: Dose-volume histograms; PTV: Planning target volume; ECG: Electrocardiography; HU: Hounsfield unit; 3D: Three-dimensional.

\section{Acknowledgements}

The authors thank Ming-Fen Lee ${ }^{1}$ and Wei-Hsun Wang ${ }^{3}$ for their kind assistance in dosimetric and imaging data collection.

\section{Authors' contributions}

Y-HL: Conception and design, Acquisition of data, Analysis and interpretation of data, Drafting of the manuscript, Critical revision of the manuscript, Final approval of the manuscript; guarantor of integrity of the entire study, definition of intellectual content; literature research, clinical studies, Obtaining funding, Administrative, technical or material support. HHWC: Conception and design, Critical revision of the manuscript, Final approval of the manuscript; guarantor of integrity of the entire study, Supervision. Y-ST: Conception and design, Analysis and interpretation of data, Critical revision of the manuscript, Final approval of the manuscript; guarantor of integrity of the entire study, statistical analysis, definition of intellectual content; literature research, Administrative, technical or material support, Supervision. All authors read and approved the final manuscript.

\section{Funding}

This study was funded by National Cheng Kung University Hospital, College of Medicine, National Cheng Kung University, Tainan, Taiwan (Grant Number NCKUH-10803028).

\section{Availability of data and materials}

The datasets analyzed during the current study are available from the corresponding author on reasonable request.

\section{Declarations}

\section{Ethics approval and consent to participate}

All procedures performed in studies involving human participants were in accordance with the ethical standards of the institutional and/or national research committee and with the 1964 Helsinki declaration and its later amendments or comparable ethical standards.

\section{Consent for publication}

The waiver of informed consent in this study was approved by the institutional review board of National Cheng Kung University Hospital.

\section{Competing interests}

The authors declare that they have no competing interests. 


\section{Author details}

${ }^{1}$ Department of Radiation Oncology, National Cheng Kung University Hospital, College of Medicine, National Cheng Kung University, Tainan, Taiwan. ${ }^{2}$ Department of Oncology, National Cheng Kung University Hospital, College of Medicine, National Cheng Kung University, Tainan, Taiwan. ${ }^{3}$ Department of Medical Imaging, National Cheng Kung University Hospital, College of Medicine, National Cheng Kung University, No. 138 Sheng-Li Rd, Tainan, Taiwan. ${ }^{4}$ Institute of Clinical Medicine, College of Medicine, National Cheng Kung University, Tainan, Taiwan.

Received: 17 August 2021 Accepted: 20 October 2021

Published online: 02 November 2021

\section{References}

1. Darby SC, Ewertz M, McGale P, Bennet AM, Blom-Goldman U, Bronnum $D$, et al. Risk of ischemic heart disease in women after radiotherapy for breast cancer. N Engl J Med. 2013;368(11):987-98.

2. van den Bogaard VA, Ta BD, van der Schaaf A, Bouma AB, Middag AM, Bantema-Joppe EJ, et al. Validation and modification of a prediction model for acute cardiac events in patients with breast cancer treated with radiotherapy based on three-dimensional dose distributions to cardiac substructures. J Clin Oncol. 2017:35(11):1171-8.

3. da Silva RMFL. Effects of radiotherapy in coronary artery disease. Curr Atheroscler Rep. 2019;21(12):50.

4. Fajardo LF, Stewart JR, Cohn KE. Morphology of radiation-induced heart disease. Arch Pathol. 1968;86(5):512-9.

5. Fajardo LF, Stewart JR. Experimental radiation-induced heart disease. I. Light microscopic studies. Am J Pathol. 1970;59(2):299-316.

6. Peretto G, Lazzeroni D, Sartorio CL, Camici PG. Cardiotoxicity in oncology and coronary microcirculation: future challenges in theranostics. Front Biosci (Landmark Ed). 2017;22:1760-73.

7. Huddart RA, Norman A, Shahidi M, Horwich A, Coward D, Nicholls J, et al. Cardiovascular disease as a long-term complication of treatment for testicular cancer. J Clin Oncol. 2003;21(8):1513-23.

8. Preston DL, Shimizu Y, Pierce DA, Suyama A, Mabuchi K. Studies of mortality of atomic bomb survivors. Report 13: Solid cancer and noncancer disease mortality: 1950-1997. Radiat Res. 2003;160(4):381-407.

9. Schultz-Hector S, Trott KR. Radiation-induced cardiovascular diseases: is the epidemiologic evidence compatible with the radiobiologic data? Int J Radiat Oncol Biol Phys. 2007;67(1):10-8.

10. Hatoum OA, Otterson MF, Kopelman D, Miura H, Sukhotnik I, Larsen BT, et al. Radiation induces endothelial dysfunction in murine intestinal arterioles via enhanced production of reactive oxygen species. Arterioscler Thromb Vasc Biol. 2006;26(2):287-94

11. Elias-Smale SE, Proenca RV, Koller MT, Kavousi M, van Rooij FJ, Hunink MG, et al. Coronary calcium score improves classification of coronary heart disease risk in the elderly: the Rotterdam study. J Am Coll Cardiol. 2010;56(17):1407-14.

12. Lee J. Coronary artery calcium scoring and its impact on the clinical practice in the era of multidetector CT. Int J Cardiovasc Imaging. 2011;27(Suppl 1):9-25.

13. Yeboah J, McClelland RL, Polonsky TS, Burke GL, Sibley CT, O'Leary D, et al. Comparison of novel risk markers for improvement in cardiovascular risk assessment in intermediate-risk individuals. JAMA. 2012;308(8):788-95.

14. Agatston AS, Janowitz WR, Hildner FJ, Zusmer NR, Viamonte M Jr, Detrano R. Quantification of coronary artery calcium using ultrafast computed tomography. J Am Coll Cardiol. 1990;15(4):827-32.

15. Kavousi M, Elias-Smale S, Rutten JH, Leening MJ, Vliegenthart R, Verwoert GC, et al. Evaluation of newer risk markers for coronary heart disease risk classification: a cohort study. Arch Intern Med. 2012;156(6):438-44.

16. Lakoski SG, Greenland P, Wong ND, Schreiner PJ, Herrington DM, Kronmal RA, et al. Coronary artery calcium scores and risk for cardiovascular events in women classified as "low risk" based on Framingham risk score: the multi-ethnic study of atherosclerosis (MESA). Arch Intern Med. 2007;167(22):2437-42.
17. Pletcher MJ, Tice JA, Pignone M, Browner WS. Using the coronary artery calcium score to predict coronary heart disease events: a systematic review and meta-analysis. Arch Intern Med. 2004;164(12):1285-92.

18. Breast. In: Edge SB BD, CC, Fritz AG, Greene FL, Trotti A, editors. AJCC cancer staging manual, 7th edn. New York: Springer, 2010. p. 345-76.

19. Fiorentino A, Mazzola R, Naccarato S, Giaj-Levra N, Fersino S, Sicignano $\mathrm{G}$, et al. Synchronous bilateral breast cancer irradiation: clinical and dosimetrical issues using volumetric modulated arc therapy and simultaneous integrated boost. Radiol Med. 2017;122(6):464-71.

20. Corvò R, Ricchetti F, Doino D, Torielli P, Agostinelli S, Cavagnetto F, et al. Adjuvant hypofractionated radiotherapy with weekly concomitant boost for women with early breast cancer: the clinical experience at Genoa university. Anticancer Res. 2010;30(11):4749-53.

21. Fiorentino A, Mazzola R, Giaj Levra N, Fersino S, Ricchetti F, Di Paola G, et al. Comorbidities and intensity-modulated radiotherapy with simultaneous integrated boost in elderly breast cancer patients. Aging Clin Exp Res. 2018;30(5):533-8.

22. Feng M, Moran JM, Koelling T, Chughtai A, Chan JL, Freedman L, et al. Development and validation of a heart atlas to study cardiac exposure to radiation following treatment for breast cancer. Int J Radiat Oncol Biol Phys. 2011;79(1):10-8

23. Azour L, Kadoch MA, Ward TJ, Eber CD, Jacobi AH. Estimation of cardiovascular risk on routine chest CT: Ordinal coronary artery calcium scoring as an accurate predictor of Agatston score ranges. J Cardiovasc Comput Tomogr. 2017;11(1):8-15.

24. Budoff MJ, Nasir K, Kinney GL, Hokanson JE, Barr RG, Steiner R, et al. Coronary artery and thoracic calcium on noncontrast thoracic CT scans: comparison of ungated and gated examinations in patients from the COPD Gene cohort. J Cardiovasc Comput Tomogr. 2011;5(2):113-8.

25. McClelland RL, Chung H, Detrano R, Post W, Kronmal RA. Distribution of coronary artery calcium by race, gender, and age: results from the MultiEthnic Study of Atherosclerosis (MESA). Circulation. 2006;113(1):30-7.

26. Takx RAP, Vliegenthart R, Schoepf UJ, Pilz LR, Schoenberg SO, Morris PB, et al. Coronary artery calcium in breast cancer survivors after radiation therapy. Int J Cardiovasc Imaging. 2017;33(9):1425-31.

27. Tjessem KH, Bosse G, Fossa K, Reinertsen KV, Fossa SD, Johansen S, et al. Coronary calcium score in 12-year breast cancer survivors after adjuvant radiotherapy with low to moderate heart exposure-relationship to cardiac radiation dose and cardiovascular risk factors. Radiother Oncol. 2015;114(3):328-34

28. Altınok P, Korkmaz L, Altınok A, Beşe N. Were we able to reduce cardiac doses in breast cancer radiotherapy over time? Eur J Breast Health. 2021;17(2):145-9.

29. Giordano SH, Kuo YF, Freeman JL, BuchholzTA, Hortobagyi GN, Goodwin JS. Risk of cardiac death after adjuvant radiotherapy for breast cancer. J Natl Cancer Inst. 2005;97(6):419-24.

30. Taylor CW, Nisbet A, McGale P, Darby SC. Cardiac exposures in breast cancer radiotherapy: 1950s-1990s. Int J Radiat Oncol Biol Phys. 2007;69(5):1484-95.

31. Sardaro A, Petruzzelli MF, D’Errico MP, Grimaldi L, Pili G, Portaluri M. Radiation-induced cardiac damage in early left breast cancer patients: risk factors, biological mechanisms, radiobiology, and dosimetric constraints. Radiother Oncol. 2012;103(2):133-42.

32. Jacob S, Camilleri J, Derreumaux S, Walker V, Lairez O, Lapeyre M, et al. Is mean heart dose a relevant surrogate parameter of left ventricle and coronary arteries exposure during breast cancer radiotherapy: a dosimetric evaluation based on individually-determined radiation dose (BACC ARAT study). Radiat Oncol. 2019;14(1):29.

33. Raggi P. Coronary calcium on electron beam tomography imaging as a surrogate marker of coronary artery disease. Am J Cardiol. 2001;87(4a):27a-34a.

34. Takx RA, de Jong PA, Leiner T, Oudkerk M, de Koning HJ, Mol CP, et al. Automated coronary artery calcification scoring in non-gated chest CT: agreement and reliability. PLoS ONE. 2014;9(3):e91239.

35. Gernaat SA, Isgum I, de Vos BD, Takx RA, Young-Afat DA, Rijnberg N, et al. Automatic coronary artery calcium scoring on radiotherapy planning CT scans of breast cancer patients: reproducibility and association with traditional cardiovascular risk factors. PLoS ONE. 2016;11(12):e167925. 
36. Xie X, Greuter MJ, Groen JM, de Bock GH, Oudkerk M, de Jong PA, et al. Can nontriggered thoracic CT be used for coronary artery calcium scoring? A phantom study. Med Phys. 2013;40(8):081915.

37. Xie X, Zhao Y, de Bock GH, de Jong PA, Mali WP, Oudkerk M, et al. Validation and prognosis of coronary artery calcium scoring in nontriggered thoracic computed tomography: systematic review and meta-analysis. Circ Cardiovasc Imaging. 2013;6(4):514-21.
38. Boda-Heggemann J, Knopf AC, Simeonova-Chergou A, Wertz H, Stieler F, Jahnke A, et al. Deep inspiration breath hold-based radiation therapy: a clinical review. Int J Radiat Oncol Biol Phys. 2016;94(3):478-92.

\section{Publisher's Note}

Springer Nature remains neutral with regard to jurisdictional claims in published maps and institutional affiliations.
Ready to submit your research? Choose BMC and benefit from:

- fast, convenient online submission

- thorough peer review by experienced researchers in your field

- rapid publication on acceptance

- support for research data, including large and complex data types

- gold Open Access which fosters wider collaboration and increased citations

- maximum visibility for your research: over $100 \mathrm{M}$ website views per year

At BMC, research is always in progress.

Learn more biomedcentral.com/submissions 